\title{
Authorship in A Scientific Article
}

\section{Md Badruddoza ${ }^{1 *}$}

'Head, Department of Pediatrics Chattagram Maa-O-Shishu Hospital Medical College Chittagong, Bangladesh.
*Correspondence to:

\section{Professor (Dr.) Md Badruddoza}

Editor-in-Chief

CMOSHMC Journal

\&

Head, Department of Pediatrics

Chattagram Maa-O-Shishu Hospital Medical College

Chittagong, Bangladesh.

Mobile : +8801819318764

Email : badrud_doza@yahoo.com

www.banglajol.info/index.php/CMOSHMC
Authorship is one of the most vital issues in writing a scientific article. In a country where corruption is rampant, you can't be sure that there would be no intellectual theft in any form. As an editor of a scientific journal over the last 2 years, I had the opportunity to see this inner face many a time. The latest evidence that came in our hand is an original article that copied from a foreign journal submitted to our journal without any alternation. The article is authored by 4 persons, 2 of them are in the rank of Associate Professor of a medical college. We have discussed the case in our Board of Editors meeting and in Academic Council and suggestions came to report the matter to the authors, to their principals/directors and even to report to BMDC (Bangladesh Medical and Dental Council).

A person must have intellectual contribution to an article to be an author from its conception to compilation. To conceive an idea and to design the study is the most important aspect of authorship. Data collection by itself is not a part of authorship but if the data collection needs the intellectual exercise of a professional than that may be considered for authorship. Analysing the data and compilation of the article are part of the authorship.

Corruption in authorship is taking many forms. One is copying fully or partly and claiming oneself as the author of an article. The other one is donating the authorship to colleagues, to spouses, to friends, and to professors. Though the first form is rare, the second form is rampant in our country. The first form can be detected by plagiarism detector that is available in online for free or on payment. The second form is sometimes difficult to identify. Statement of contribution by each author is not enough if the main author tries to conceal the fact and tries to cover by misinformation. Honesty and integrity is very important on the part of authors. The practice will be decreased if only the first authors of scientific articles are given credit in considering promotion in a professional career in context of Bangladesh.

An author is a very prestigious status. Any academician would prefer to be an author at the same time. But it is a bit different skill than being a simple academician. We see great academician in our past generation but very few of them were authors. Writing scientific articles was not a prerequisite at that time, but now it is an essential art that a teacher must attain. I personally feel that the number of original articles that is assigned to each category should be increased.

To develop the skill of writing is not an easy thing. In relation to a scientific article, it is more true. In our curriculum research methodology and biostatistics have not given due importance in undergraduate over the years. In postgraduate curriculum also it is not duly stressed. There is little scope in undergraduate to exercise scientific studies and to publish them. In the post-graduate level, it is then becoming difficult to comprehend the ideas, to organize the studies, to analyze and to compile the work. A holistic approach is needed to improve the situation and to bring our medical students and doctors at par with the scientific world.

\section{DISCLOSURE}

The author declared no competing interest. 


\section{REFERENCES}

1. Defining the Role of Authors and Contributors, International Committee of Medical Journal Editors,

http://www.icmje.org/recommendations/browse/roles-and-responsibilities/defining-the-role-of-authors-and-contributors.html.

2. Conventions of scientific authorship, Science, Vijaysree Venkatraman, Apr. 16, 2017.

http://www.sciencemag.org/careers/2010/04/conventions-scientific-authorship

3. The Ethics of Authorship: Policies for Authorship of Articles Submitted to Scientific Journals. http://provost.yale.edu/policies/academic-integrity/guidance-authorship-scholarly-or-scientific-publications.

4. Guidance on Authorship in Scholarly or Scientific Publications

http://provost.yale.edu/policies/academic-integrity/guidance-authorship-scholarly-or-scientific-publications.

\section{CORRIGENDUM}

The CMOSHMC Journal is disowning the article titled "Complications of Spinal Anaesthesia in Caesarean Section in A Tertiary Care Hospital Chittagong, Bangladesh" authored by Dr. Md Monirul Alam, Dr. Khairul Anwar, Dr. Muslina Akter \& Dr. Rajat Kumar Biswas published in Volume 15, Issue 2, July 2016 as the article is mostly copied from an article published in Pakistan Journal of Medical \& Health Sciences, originally written by Dr. Farhat Naz et al, Department of Obstetrics and Gynaecology, Allama Iqbal Medical College/Jinnah Hospital, Lahore, Pakistan.

(http://pjmhsonline.com/complications_of_spinal_anaesthe.htm)

\section{Editor-In-Chief}

CMOSHMC Journal 